\title{
UREA CLEARANCE TESTS
}

BY
H. FAIRFIELD SMITH
(RECEIVED FOR PUBLICATION, JUNE 13, 1949)

\section{CONTENTS}

Introduction

I. The Van Slyke Urea Clearance Test

.. 266

II. Observations on Prisoners of War in Siam 266

1II. Comparison of Average Urea Concentrations

This paper has its origin in work done in a prisoner of war hospital camp in Siam. Under the prevailing condition of protein-starvation there the Van Slyke formulae for calculating urea clearance as a percentage of normal were found to be completely misleading. The only literature then available was a handbook of laboratory methods giving the bare routine of the test without indicating the source of factors in the formulae. Therefore an attempt was made to devise our own standards, including adjustment for the rate of urine excretion. When eventually I was able to obtain copies of the principal papers by Van Slyke and his colleagues (Austin et al., 1921 ; McIntosh et al., 1928; Möller et al., 1928) it seemed of interest to compare our results with theirs.

The initial objective was to see if the method of adjustment for the rate of urine excretion used in Siam, or a modification of it, might provide a single generally applicable formula by which procedure could be both simplified and unified in place of the two in current use. This objective was achieved (see appendix), but in the course of the work I found myself forced to the conclusion that the Van Slyke urea clearance test is useless in its present form.

\section{The Van Slyke Urea Clearance Test}

The Van Slyke urea clearance test is the ratio of the amount of urea excreted per minute in urine to the concentration of urea in blood compared with the ratios observed in a sample of laboratory workers and since accepted in the textbooks as normal.
IV. Discussion of the Van Slyke Test ...

V. Methods of Deriving Efficient Diagnostic Criteria

VI. Summary

Depending on the rate of urine excretion it is computed by one or other of two formulae.

$$
\mathrm{C}_{\mathrm{g}}=\mathrm{U} \sqrt{\mathrm{V}} / \mathrm{B} \text { when } \mathrm{V} \text { is less than about } 2 \text { (1). }
$$

$\mathrm{C}_{\mathrm{m}}=\mathrm{UV} / \mathrm{B}$ when $\mathrm{V}$ is greater than about 2 (2). where $\mathrm{V}=$ volume of urine excreted in ml. per minute.

$\mathbf{U}=$ concentration of urea in urine in $\mathrm{mg}$. $\mathbf{N}$ per $\mathrm{ml}$.

$\mathbf{B}=$ concentration of urea in blood in $\mathrm{mg}$. $\mathbf{N}$ per ml.

(Different units have been used at different times in the literature, but those quoted will be adhered to throughout this paper.)

$\mathrm{C}_{\mathrm{B}}$ is called the "standard urea clearance at a urine excretion rate of $1 \mathrm{ml}$. per minute."

$\mathrm{C}_{\mathrm{m}}$ is the "maximum clearance rate" observed at high rates of urine excretion.

The adjustment for the rate of urine excretion derives from the observation that the amount of urea excreted (UV) is approximately proportional to $\sqrt{ } \mathrm{V}$ when $\mathrm{V}$ is less than about $2 \mathrm{ml}$. per minute, and is constant when $V$ is greater than that. The accepted normals are $C_{s}=54$ with a range from 34 to $75 ; C_{m}=$ 75 with a range from 52 to 98 . Observations outside these limits are supposed to indicate renal abnormalities.

\section{Observations on Prisoners of War in Siam}

The chemical aspects of the work in Siam and the conditions under which it was done have been described by Wilshaw (1947). Data are available for 65 men. Of these, 15, termed " normals," were observed as a check on what at first seemed the abnormal results being obtained for diagnostic purposes. The other 50, "patients," were men 
sent by medical officers for observation. Available laboratory notes give clinical comments for only three cases. The case with the lowest blood urea level is recorded as one of renal colic for two years, and a case in the centre as renal colic for two years, the left kidney being palpable. The case with the highest blood urea level had blackwater fever; this man was observed again, five weeks later giving the point at $y=0.1$, $u=-0.71$. The majority of patients were sent for a precautionary test of renal efficiency before operation for removal of a kidney containing stones, but were not expected to be renally deficient.

For each man we observed the volume of, and concentration of, urea nitrogen in the urine excreted during each of two successive hours, 10 to 11 and 11 to 12 a.m. (by sun time 8 to 10 a.m.) after a breakfast of rice and weak tea at 8 a.m. (6 a.m. sun time). Only one sample of blood was taken, about the middle of the two-hour period.

The precise amounts of protein in the diets are unknown to me, but were very low. Harvey (1946) quotes diets for a Singapore camp containing 25 to $86 \mathrm{~g}$. protein per day; amounts in Siam were roughly similar, but in this particular camp probably did not sink to the lowest limit recorded at Singapore. There was undoubtedly a good deal of variation. The group of normals included some cooks who could never refrain from helping themselves to extra; some patients received supplementary diets; some men only bought eggs with their available funds, and others spent it all on tobacco; workers had more to spend than patients. (At that time an egg cost 25 sètangs. Men working for the Japanese received 25 sětangs a day, camp workers 10 sětangs, but non-working patients officially got nothing.)

Despite ersatz laboratory conditions the observations are of the same order of accuracy as those of previously published work. (The variance of deviations of $\log U$ from its regression on $V$ and $B$ was, for the normal group, 0.00263 compared with a corresponding figure for the data of McIntosh et al. of 0.00243 , or 0.00174 if days on which urea was administered are omitted. Logarithms show variability proportional to the magnitude of the variate. Since the observations recorded here are on lower concentrations, observations in units of $\mathrm{mg}$. per $\mathrm{ml}$. would appear more accurate.

Urine urea concentrations show the same correlation with the volume of urine as was observed by Van Slyke et al. This can be described by a quadratic regression between the logarithms. Using this the urine urea concentration at any given rate of excretion can be estimated without arbitrarily dividing the data into two parts as with Van Slyke's method of adjustment. (For normal conditions, not stimulated by drinking variable quantities of water, as in the cases of the prisoners or the children, Table I, a linear equation may be sufficiently accurate.) Using the regression evaluated for the patients the log urine-ureaconcentration for each man has been calculated as

$$
\hat{y}=y+0.49(v-0.174)+0.25\left(v^{2}=0.146\right)
$$

where $y, v$, and $v^{2}$ are the averages of the two observations per man of $\log \mathrm{U}, \log \mathrm{V}$, and $(\log$ V) $)^{2}$ respectively ; 0.174 and 0.146 are the overall averages of $v$ and $v^{2}$ for the 50 patients. The effect is to adjust for the rate of urine excretion to the point where greatest average accuracy is obtained, namely at $v_{\mathrm{o}}=0.223(\mathrm{~V}=1.67 \mathrm{ml}$. per minute).

Since there was only one blood urea observation per man the internal correlation of $\mathrm{V}$ and $\mathrm{B}$ cannot be evaluated. Fig. 1 shows the bivariate distribution of $\hat{y}(=\log U$ at $V=1.67)$ and $u$ $(=\log \mathrm{B})$. Obviously in these data there is no correlation of urine and blood urea levels between individuals.

The frequency distribution of observations of $\mathrm{C}_{\mathrm{s}}$ is :

$\begin{array}{llllllllll}\operatorname{lcg} C_{8} & 0.9 & 1.0 & 1.1 & 1.2 & 1.3 & 1.4 & 1.5 & 1.6 & 1.7\end{array}$ $\begin{array}{llllllllll}C_{8} & 7.9 & 10.0 & 12.6 & 15.8 & 20.0 & 25.1 & 31.6 & 39.8 & 50.1\end{array}$

$\left.\begin{array}{l}\text { Frequency } \\ \text { between } \\ \text { above values }\end{array}\right\}$
$\begin{aligned} & \text { If } \\ & \text { there }\end{aligned}$

If there were among the patients a group of renal defectives, and if the clearance ratio could detect these, we could reasonably expect a minor mode, or at least a longer tail, in the lower part of the range. These observations indicate a symmetrical distribution such as would be shown by a homogeneous group. On an arithmetic scale the tail would be at the upper instead of at the lower end.

Our records from Siam show some 45 additional observations on blood urea levels only, often with repetitions. Some of these gave very high values (particularly one just before death), but as they do not show anything unusual they need not be reported in detail. It is to be noted only that those exceeding $0.24 \mathrm{mg}$. urea- $\mathrm{N}$ per $\mathrm{ml}$. did correlate closely with clinical observations. Although the evidence is incomplete there seems little doubt that patients represented in Fig. 1, with the possible exception of the one at $B=0.34$, were renally efficient. In the subsequent discussion they will be regarded as a sample of renally normal men; the argument will not be impaired if a few were in fact diseased. 


\section{Comparison of Average Urea Concentrations}

A comparison of urea concentrations and clearance rates observed in Siam with others recorded in the literature is given in Table I. Three main groups are represented.

(1) Residents of the U.S.A. who had, presumably, a fairly high protein diet; (2) Indians on a moderate to low protein diet; (3) prisoners of war on a very low protein diet.

The leading features as they affect the urea clearance test are immediately apparent. When enabled us to detect were that some prisoners had access to extra meat.

\section{Discussion of the Van Slyke Test}

Much confusion appears to have originated in a failure to express explicitly the foundations of the test. Adjustments for variable factors have been derived on the basis of short term experimentally imposed variations within the individual, and it has been assumed that such adjustments were valid for comparison of permanent differ-

TABLE I

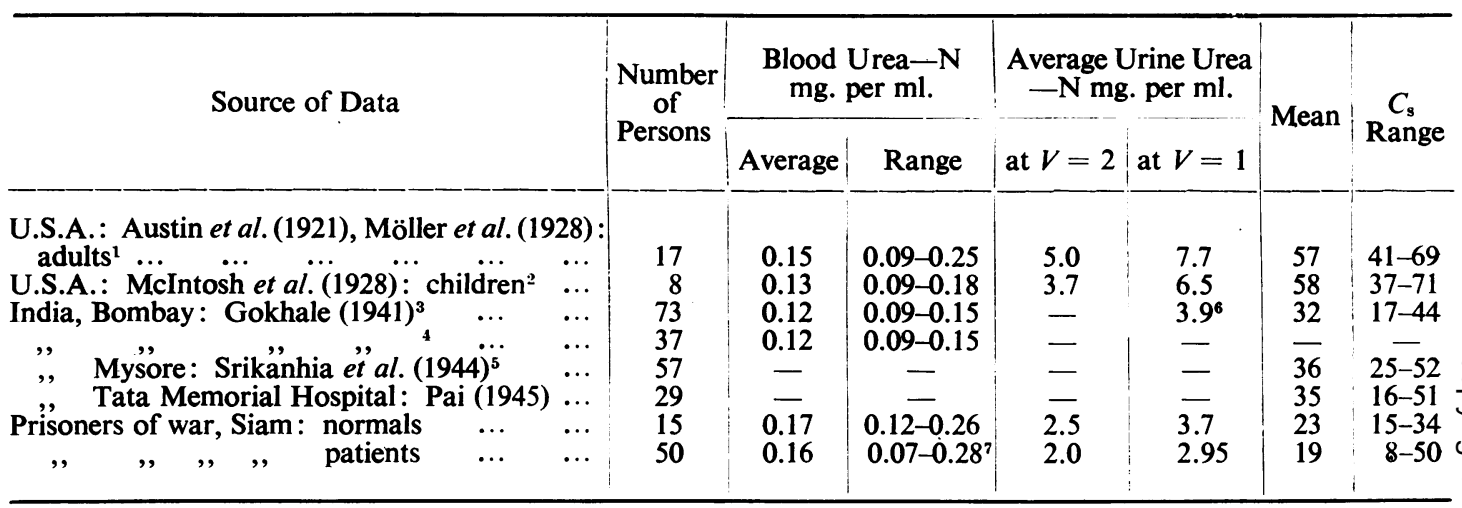

1 Data for days when no urea was administered. Both limits of B shown by one person (FC); range of means per person 0.10 to 0.19 . 2 Adjusted to height $=175 \mathrm{~cm}$., using regression of $\log U$ on $\log$ height $=1.5$. Range of $B$ for means per person 0.11 to 0.17 .

3 Group for which standard clearances were computed.

\footnotetext{
4 Group for which maximum clearances were computed.

5 Taken from data quoted by Pai.

6 Calculated from average $C_{8} \times B$.

7 Omitting two highest observations, 0.34 and 0.44 .
}

diet is altered and the body is given time to readjust its balance to the new conditions, blood urea concentration is maintained at the same level as usual, in Europeans about 0.15 to $0.16 \mathrm{mg}$. urea- $\mathrm{N}$ per $\mathrm{ml}$. The blood urea concentration does not respond to a permanent alteration of protein intake in the same way as it does temporarily to a dose of urea or to an exceptional meat meal. Therefore blood urea concentration is not in general an index of the amount of urea available for excretion, which, obviously, must balance with protein intake. This means that between individuals on permanently different diets urea concentration in blood tends to be approximately constant, whereas in the urine it is proportional to the protein consumed. Therefore in healthy persons the ratio depends on the diet, and a test case can give no useful information on other things unless it be related to a normal derived specifically from the average diet of the subject. In Siam the only abnormalities which the test ences between individuals. In particular it has been assumed that the ratio of urine urea to blood urea makes allowance for variation in the amount of urea available for excretion, in other words, for variation in diet.

That assumption is essential for the validity of the test as it is usually applied, and yet I am uncertain whether or not it has been made consciously. More recent work seems to imply that the ratio is a characteristic worthy of study in its own right. This point of view will be discussed in section $V$. That it was eventually assumed to allow for differences in diet is made clear by the following quotation (Möller et al., 1928):

- In subjects with such renal loss the blood urea may, in fact, even be less than the normal average. Thus in experiments $10 \mathrm{a}$ and $20 \mathrm{c}$ blood urea nitrogen of only 10 to $12 \mathrm{mg}$. per $100 \mathrm{c.cm}$. is seen, despite the fact that both subjects showed only about $40 \%$ of 
normal excreting power. Such results indicate the uncertainty attending interpretation of normal blood urea values in nephritic patients if the urea excretion rate is not also taken into consideration. It has in fact been common on our wards to find consistently normal blood ureas in nephritic patients who have lost $40-60 \%$ of their renal function. Such patients are likely, either by choice or direction, to take diets low in protein; and if they consume half as much as a given normal subject, other factors being equal, they will show about normal blood urea content."

This implies that these men have normal blood urea only because they are eating little protein, and that a normal man on their diet would have lower blood urea, so that the urine/blood urea ratio would be less affected than the urine urea concentration itself. Our observations show that a normal man eating little protein would show precisely the same urea clearance as these patients. The test cannot differentiate between the two.

A review in Nature (Srikanhia and Shamanna, 1945 ) of the Indian observations commented:

"The figures of Gokhale and of Srikanhia and Shamanna suggest that the Indian kidney has only about two-thirds the efficiency of its American counterpart."

The remark is typical of numerous others occurring throughout the literature. The urea clearance rate having become established as a measure of renal efficiency it has become customary to write, without thought that the measure may be faulty, "renal efficiency is low," when what is meant is that " the ratio of urine urea to blood urea concentration is low compared with the ratio observed in a small group of Americans." Our data show that observations of an extremely low urea clearance rate $\left(C_{s}=10\right.$, or $18 \%$ of the accepted normal) may have nothing whatever to do with renal inefficiency. The kidneys of all groups recorded in Table I were correctly performing their function of keeping excretion in balance with intake and so were fully efficient. Differences in their clearance rates measure only the protein diets of the subjects.

\section{Methods of Deriving Efficient Diagnostic Criteria}

The object of a clinical test is to discriminate between conditions of health and disease. There must be some criteria to which the results of a test can be referred in order to make a decision. In general there will be no hard and fast line between health and disease. In order to have a logical basis for deciding the levels at which criteria should be set and for knowing just what subsequent tests may mean, it is necessary to consider the probability of a wrong diagnosis. The criteria should depend on some decision as to the relative seriousness of considering a person diseased when he is in fact healthy, or vice versa. The probability of the former can be assessed when the frequency distribution of the observation is known for a normal population similar in all respects to a population to be tested, except for occurrence of abnormalities of the kind being sought (Neyman's error of the first kind). The probability of the reverse will depend on how far the diseased condition is removed from normality, and consequently can only be assessed for specified degrees of abnormality (Neyman's error of the second kind).

If only one characteristic is observed the problem is merely to fix the point on a single scale where the probabilities of either error are reasonably balanced. But when two or more characters are observed we have a choice of numerous types of region which may be demarcated with equal probability of an error of the first kind. We have to consider which of these regions will maximize the power of the test to discern the abnormality in question.

To illustrate: let us assume that the 65 observations depicted in Fig. 1 form a representative sample of urea concentrations in urine and in blood for renally normal persons in the camp where they were observed. Suppose we decide to accept a $5 \%$ risk of an error of the first kind, that is of declaring a person abnormal when he is not. The problem is to demarcate a region of Fig. 1 containing $5 \%$ of the normal population in which an abnormal observation is likely to lie. To do this we also require evidence of the region (or regions) in which abnormal observations may occur. It has been noted that all the patients definitely diagnosed as renally defective had blood urea $(\mathrm{N})$ greater than $0.24 \mathrm{mg}$. per $\mathrm{ml}$. Therefore the only line we can reasonably draw on present evidence is the vertical line B. (The criterion for its position is that it is 1.6 times the standard deviation of $u$ from the general mean, that is at a point estimated to mark off the upper $5 \%$ of the population on the hypothesis that it is normally distributed.) On that criterion the test is based on blood urea concentration alone without consideration of $U$ (or $\hat{y}$ ). In the absence of more comprehensive evidence it is at least a reasonable criterion, since a high blood urea level is undoubtedly direct indication of disease. A criterion based on the urine urea concentration 
alone would reject observations below the line $\mathrm{A}$. The evidence of Table I indicates that this is primarily a criterion of diet, an indication which is consistent with the relative position of the normals (Fig. 1) who, being wage earners, would be in a better position than many of the patients to obtain supplementary food. Any line not parallel to A or $B$ entails combination of both variates.

The procedure of the Van Slyke urea clearance test is to demarcate regions by lines at $45^{\circ}$ to either axis.* For a $5 \%$ risk of error of the first kind this would be line $S$ (which, it may be noted incidentally, would reject the blackwater fever case after he had returned to health).

The reasons for selecting this region can well be described as little more than a "hunch" that it might be informative. It is at first sight reasonable to suppose that when renal function begins to fail some increase in the blood urea level may be accompanied by a decrease of urea excretion relative to protein intake and blood urea concentration, and that the failure may be more quickly detected by considering both simultaneously than either one alone. There is, however, no a priori reason to suppose that the two effects occur in inverse proportion.

A method to determine the combination of two or more characters which may best discriminate between two groups has been described by $\mathbf{R}$. A. Fisher $(1936 ; 1946)$. Clearly in this case, since $U$ has been shown to be closely linked to protein nutrition, quantities of protein consumed would need to be introduced as a fifth variate in addition to $\mathrm{U}, \mathrm{V}, \mathrm{B}$, and body size. The efficient discriminant function depends on the relative errors of

*As has been noted, the observations $\hat{y}$ in Fig. 1 are $\log U$ adjusted to vo $=0.223$. The estimates of $\log U_{1}$ at $\mathrm{V}=1$ are given by

$$
y_{1}=\hat{y}+0.49 v_{0}+0.25 v_{0}^{2}=\hat{y}+0.1217
$$

consequently contours of $C_{B}=U_{1} / B$ in Fig. 1 are given by equations

$$
\hat{y}=\log C_{s}-0.1217+u
$$

observations on each variate as well as on their physiological relationships. $\dagger$

The following considerations make it seem unlikely that a function of these five variates will be appreciably more effective to detect renal deficiency than will observation of blood urea levels alone. Either urea excreted must balance protein consumed, or blood urea must be increasing. If the kidneys are not functioning efficiently, presumably the excretion required to balance intake may be achieved by a higher concentration in the blood. If the patient in that way maintains a stationary position his urine must be normal for his diet (if it can be assumed that excretion in sweat is not materially increased), and therefore the condition is shown by a high blood urea level only. If the urea excreted is less than the intake, either the balance not excreted must be very small or blood urea must be increasing rapidly. It seems unlikely

+ Since the first draft of this paper was written (December 1947) I have learnt that suggestions to apply these ideas to ciinical 1947) I have learnt that suggestions to apply these ideas to ciinical
medicine have also been made by others. A paper for presentamedicine have also been made by others. A paper for presentation to a conference of the Royal Statistical Society in October, 1948, by R. B. Fisher, was entitled "An Application of Discriminants to Clinical Chemistry." So far as I know this is no work in the U.S.A. has also been reported. 
that determinations of urea in urine may be sufficiently accurate to detect the first of these conditions. In the second no refinement on observation of blood urea alone is likely to be required. Nevertheless the possibilities merit further investigation.

Addis proposed observation of the clearance ratio when supplementary urea was administered, and this is the test chiefly considered by Cope (1934). We had no means in Siam of artificially increasing blood urea concentrations and are not in this paper concerned with circumstances thus created except as they affect interpretation of the data of Möller et al. Presumably diet would not affect the response of normal subjects to extra urea; and, if it can be shown that renally defective individuals react differently, this test might be of some use when referred to observations on the same individual "at rest" rather than to fixed standards.

Some observations by Van Slyke (1947) suggest that observation of the slope and curvature of the regression of $\log \mathrm{U}$ on $\log \mathrm{V}$ at low urination rates might be informative. This will, however, be very susceptible to differing abilities to evacuate more or less completely, and artificial methods might have to be used.

A more important defect in the procedure used to set criteria for the urea clearance test is illustrated by Fig. 1. The limits accepted as normal were simply the highest and lowest ratios observed in a casual sample of 18 subjects who seem to have been mostly workers in the laboratory. Our sample of 15 normals (about the same size of sample) was drawn in a similar way, being workers nearly all from one hut. Following the same procedure our lower criterion would have been given by a line through the point $D$ and parallel to $S$. This would have resulted in classing $27 \%$ of our patients as renally deficient, which would have been manifestly erroneous. The reasonable explanation is that workers probably had better food than many patients. Analogous differences occur between the original laboratory sample of Van Slyke et al. and patients subsequently tested who, being suspected of renal defect, would often have been given protein-low diet. The lower criterion derived in that way, and since 1928 accepted as the dividing line for test purposes, is shown by the dotted line in Fig. 1. It would condemn $95 \%$ of those we observed, including all the normals, as renally defective.

The moral is that observations from which a clinical criterion is to be derived must be properly representative of the population to which the test is to be applied. Furthermore, in order accurately to assess the probability of error the sample must be large, say, 500 to 1,000 persons. Confidence limits derived from the $t$ test of small sample theory are not satisfactory for setting control limits (Deming and Birge, 1938). The labour required will be small compared to the waste in applying tests whose reliability is unknown and undefined. It should be noted too that the essential requirement is observations on a large number of persons, not many observations on a few. Single observations per person would serve, but duplicates would be preferable to control gross accidental errors, and to obtain estimates of sampling variance within and between persons, say $V_{e}$ and $V_{\mathrm{p}}$. The error variance of a mean of $n$ observations on one individual is then given by $V_{n}+$ $V_{\mathrm{e}} / n$; and the efficient number of observations to make in any given circumstances will depend on balancing the cost of $n$ observations against value of consequent accuracy.*

\section{Summary}

Observations on prisoners of war in Siam show that when diet contains little protein the blood urea concentration is still maintained at normal levels while urea excreted in urine is greatly reduced, as of course it must be to balance with the amount of protein consumed. Underlying the Van Slyke urea clearance test is the assumption that, by observing the ratio of urea in urine to its concentration in blood, allowance is made for the effect of diet on urine urea. That assumption is shown to be false. Consequently the urea clearance test as generally used without reference to diet is not a trustworthy measure of "renal efficiency" and may be completely misleading. Men with efficient kidneys were observed to have a "standard urea clearance" as low as 10 , or $18 \%$ of the accepted normal.

The reasoning which led to setting misleading criteria for this test is discussed. It seems that observations on urine urea are unlikely to be of much use in testing for renal efficiency, but the possibilities should be further investigated. Methods for doing so and for deriving efficient criteria for clinical tests in general are indicated.

The observations on prisoners of war were made in the pathology laboratory of the camp at Nakom Patom, Siam, from January to July, 1945, by Major A. T. H. Marsden, R.A.M.C., pathologist, Malayan

* Mr. B. G. Greenberg, research graduate in medical statistics, Institute of Statistics of the University of North Carolina, who kindly read the first draft of this paper, points out that sequential testing might profitably be used in clinical tests. This means that the probability of error is assessed after each observation. If the first observation indicates reasonable certainty it is accepted as final, but if it leaves more than the permissible margin of doub then further observations are made until an answer is obtained at the required confidence level. (The theory is expounded in several papers by Barnard and others and in Sequential Analysis of Statistical Data.) 
Medical Service, who was director of the laboratory, and by Major R. G. H. Wilshaw, chemist, Department of Agriculture, Malaya. The writer was at the time working in the laboratory as a biologist, but has been concerned with these data only as a statistician. I am indebted to the observers for putting their ingeniously obtained data at my disposal without restriction.

I should like further to record my appreciation of the courtesy shown by Professor G. R. Cameron, Dr. H. D. Barnes, and Dr. D. D. Van Slyke in discussing this work with an interloper led by circumstances of fate into a field not his own. Dr. Barnes brought to my attention the Indian work, which has therefore been added since the original draft of this paper, and provides welcome corroboration of work done under difficulties which might otherwise have been suspected of throwing doubt on their freedom from systematic error.

Dr. Van Slyke has brought to my attention several other papers on the effect of dietary protein and urine volume on urea clearance (Cope, 1933; Van Slyke et al., 1934; Farr, 1936; Longley and Miller, 1942 ; Van Slyke, 1947). It may, however, be helpful to note that most of them appear to deal with comparatively short periods on altered diets and to consider only the ratio urine/blood ureas without attempting to follow alterations in urine urea and in blood urea separately. It seems that an abrupt change of diet rapidly alters blood urea concentration which returns to normal only gradually, hence the correlation between blood urea and urine urea noted by Van Slyke, but not shown among the prisoners. The full effect of altered diets on the ratio is therefore not apparent in short-term experiments. There is also a hint, in the observations of Van Slyke and in those on the prisoners of war, that stimulus from temporarily increased blood urea (either by administration of urea or by blackwater fever) may result in subsequent depression of blood urea. If so, it adds another reason for regarding the orginal data of Van Slyke as unsuitable for determination of criteria to be used in a test without that stimulus. These points require further investigation.

\section{REFERENCES}

Austin, J. H., Stillman, E., and Van Slyke, D. D. (1921). J. biol. Chem., 46, 91.

Cope, C. L. (1933). J. clin. Invest., 12, 567.

Cope, (1934). Lancet, 2, 799.

Deming, W. Edwards, and Birge, R. T. (1938). On the theory of errors. Additional notes, 1938. Foreword to reprint by Grad. School, U.S.D.A.

Farr, L. E. (1936). J. clin. Invest., 15, 703.

Fisher R. (1936). Ann. Eugen, 7, 17.

Fisher, 1946). Statistical Methods for Research Workers. 10th ed. Oliver and Boyd, Edinburgh.

Gokhale, S. K. (1941). Indian J. med. Res., 29, 627.

Harvey, C. (1946). Med. J. Aust., 1, 769.

Longley, L. P., and Miller, M. (1942). Amer. J. med. Sci., 203, 253. Mclntosh, J. F., Möller, E., and Van Slyke, D. D. (1928): J. clin. Invest., 6, 467.

Möller, E., McIntosh, J. F., and Van Slyke, D. D. (1928a). Ibid., 6, 485.

Pai, M. L. (1945). Indian J. Ibid., 6, 427.

Pai, M. L. (1945). Indian J. med. Res., 33, 259.

Smith, H. Fairfield (1936). Ann. Eugen., 7, 240.
Srikanhia, C., and Shamanna, D. (1944). Proc. Ind. Acad. Sci., 19, 121 .

Van Slyke, D. D. (1947). J. clin. Invest., 26, 1159.

- Rhoads, C. P., Hiller, A., and Alving, A. S. (1934). Amer. J. Physiol., 110, 387.

Wilshaw, R.'G. H. (1947). Pharm. J., reprinted in Malayan Agric. J., 30. 27.

\section{APPENDIX}

Relation Between Urea Concentration in Urine, Rate of Urine Excretion, Urea Concentration in Blood, and Body Size

From statistical analysis of the data of Van Slyke et al., and from observations of the prisoners of war, the following conclusions were reached.

The relation of urea concentration in urine $(U)$ to the rate of urine excretion $(V)$ may be described by an equation of the form

$$
\log U=A-\log (a+V)
$$

or, more empirically, by

$$
\log U=a-0.48 \log V-0.3(\log V)^{2}
$$

Curvature shown by different individuals varies considerably. The constants given are average values which may serve sufficiently well, when the number of observations on a person are too few to determine his own characteristic curve, to estimate urine urea concentrations for comparison with others. Adding regression on body height, a convenient equation to estimate urine urea concentration $(\hat{U})$ at any fixed urination rate $\left(V_{0}\right)$ and height $\left(H_{0}\right)$ is

$\log \hat{U}=\log U+0.48\left(\log V-\log V_{\mathrm{o}}\right)+0.3\left(\log ^{2} V-\right.$ $\left.\log ^{2} V_{\mathrm{o}}\right)-1.5\left(\log H-\log H_{\mathrm{o}}\right)$

where $U, V$, and $H$ are observed values.

The two curves used by Van Slyke et al. to estimate urine urea concentrations at fixed urination rates areo a reasonable approximation to the actual curve, bu the consequent partitioning of data into two parts when such estimates are required is a nuisance and inefficient. Their "augmentation rate" is artificial. It does roughly indicate a point where the curve approaches close to its asymptote and beyond which it may be considered to be straight, but it is not a satisfactory statistic for comparison of different curves.

The hypothesis of Möller, McIntosh, and Van Slyke (1928a) that, at a given rate of urination, urine urea concentration is proportional to body size appears to be justified. Their further opinion that no accuracy is gained by trying to estimate surface area from weight as well as height is also confirmed. Their procedure for doing this is, however, circuitous and confusing. It would simplify computations and show better exactly what is being done if adjustment were based explicitly on height instead of on a supposititious body area.

When the blood urea level is temporarily increased by administration of urea or by a heavy meat meal. urine urea is increased nearly but not quite in proportion ; actually in proportion to about the 0.85 th power of blood concentration. But for variations occurring with normal diet the relationship appears to be less close. Between different persons on variable diets there is no appreciable correlation. 